\title{
Media Representations of Bipolar Disorder Through the Case of Suzy Favor Hamilton
}

\author{
Rachel Vaccaro and Ted M. Butryn \\ San Jose State University
}

\begin{abstract}
Individuals suffering from mental illness face challenges that are related to stigma and lack of education that are often reinforced by the media. Specifically, the elite athletic culture is not conducive for athletes who suffer from mental illness because there is at times a belief that mental illnesses are less prevalent in elite sport. Even though incidence of mental illness in elite athletes has gained more prominence in the popular media, there is still a lack of research in this area. Specifically, there is limited research regarding media representations of athletes who suffer from mental illness. To address this gap in the literature, an ethnographic content analysis (ECA) was done to examine Suzy Favor Hamilton's open discussion of bipolar disorder surrounding the release of her new memoir, Fast Girl: A Life Spent Running From Madness. ECA yielded one overarching theme with three supporting sub-themes. Results indicated that even though Favor Hamilton's book worked to spread awareness, the media attention surrounding the book release represented omission of mental illness in the environment of athletics. Overall, sports culture provides an environment that is not often willing to accept that mental illnesses exist in athletes.
\end{abstract}

Keywords: distance running, female athletes, media analysis, mental health

Until recently, mental illnesses in athletes have attracted less attention and media coverage than physical injuries (Newman, Howells, \& Fletcher, 2016). However, the majority of published research studies suggested that mental health conditions are just as likely to occur in athletes as they are in the general population (Beable, Fulcher, Lee, \& Hamilton, 2017; Markser, 2011; Rice et al., 2016). Rice et al.'s (2016) systematic review of mental health in elite athletes illustrated that the physical and mental tolls of competitive athletics might increase athletes' vulnerability to mental illnesses. Physical, sociological, emotional, and mental stresses might exacerbate these tolls (Markser, 2011).

Sport psychology research does not regularly address the topics of mental illness or mental health in the elite athletic population unless it is related to eating disorders or sports performance (McGannon \& McMahon, 2016). The small amount of research that touched on athletes' mental health issues tended to focus on depression because of its easily diagnosable nature (Weigand, Cohen, \& Merenstein, 2013). Newman et al. (2016) suggested that the lack of research on the etiology and occurrence of mental illness in athletes was largely related to the taboo nature of the topic as well as the notion that athletes are immune to mental illness.

Underreported, unidentified, and hidden symptoms among athletes might have also contributed to the social stigma associated with mental illness in the domain of sport (Newman et al., 2016). Negative social stigmas, or fear of them, are some of the leading causes of athlete avoidance toward help-seeking for any mental health issue they may face (Beable et al., 2017; DeLenardo \& Terrion, 2014; Pike, 2019; Rice et al., 2016). The unhealthy, alternate solutions athletes find for their mental health problems are attempting to avoid the issue, covering up the

The authors are with San Jose State University, San Jose, CA. Butryn (theodore. butryn@sjsu.edu) is corresponding author. problem, or denial (Beable et al., 2017; Rice et al., 2016; Schwenk, 2000; Weigand et al., 2013). Gucciardi, Hanton, and Fleming (2017) noted that stigma is the most prominent barrier collegiate and young elite athletes face when they evaluate their thoughts on seeking help. Sometimes even worse than the feelings toward external stigma are the internalized self-stigmas felt by athletes suffering from mental illnesses (DeLenardo \& Terrion, 2014).

One key external factor that can exacerbate mental illness is the way that media covers it. Indeed, media representations of mental illness have arguably had the greatest influence on public opinions about mental health conditions and are considered one of the most prominent contributing factors to stigmatization of mental illness (Gibson \& Gorczynski, 2019; Ma, 2017; Mellifont \& SmithMerry, 2015; Quintero Johnson \& Riles, 2016). Research shows that the media is especially persuasive when the public does not have significant background knowledge of the specific group being discussed (McGinty, Webster, Jarlenski, \& Barry, 2014). Tabloid newspapers and otherwise unreliable sources were also equally as effective as factual stories in contributing to the mental health stigma (Anderson, 2003). In the mainstream media, individuals suffering from mental illness were most often portrayed as violent, crazy, dangerous, or as a threat to society and themselves (Anderson, 2003; Fauteux, McKelvie, \& Man, 2008; Ma, 2017; McGinty et al., 2014; Mellifont \& Smith-Merry, 2015; Quintero Johnson \& Riles, 2016). Even though these were the most commonly occurring themes, these behaviors were inaccurate and rare in individuals suffering from mental illness (Ma, 2017; McGinty et al., 2014). Further, the tendency of some writers to sensationalize mental illness is often even more pronounced in stories that involve more severe conditions (McGinty et al., 2014) such as schizophrenia and bipolar disorder (Aoki et al., 2016). Of particular relevance to this study, Aoki et al.'s (2016) study evaluated schizophrenia and bipolar disorder depictions in Japan's news media. Japan changed the name of schizophrenia in 2002 to integration disorder 
to decrease social stigma and elicit the idea that even though the disease could not be eliminated it was controllable. The results showed that, "there was an increase of the ratio of articles on schizophrenia and danger to that of bipolar disorder during the first decade, and a significant decrease during the second decade" (p. 196). The results also displayed that negative depictions of bipolar disorder increased while the negativity related to articles including integration disorder and schizophrenia decreased. Overall, in this area of research, media portrayals of mental illness are negative.

Fauteux et al.'s (2008) research explored the relationship between public figures who received psychological help and the attitudes toward help-seeking from a mental health professional. Overall, their research concluded that showing public figures seeking help did not foster a more accepting attitude for helpseeking compared to providing participants with general information about psychology. Within the sporting domain, media sources have gained increased power when covering athletes because the media "play a crucial role in fostering the process of sport star making" (Tulle, 2016, p. 252). For example, Knight and Giuliano (2001) explored stereotypical portrayals of athletes in print media sources and found that if an individual violated a firmly established cultural norm, they were perceived more negatively than athletes who behaved in "acceptable" ways. However, while research on mental illness in elite athletes was scarce, studies on the media representations of mental illness, and in particular bipolar disorder, among elite were almost non-existent.

Methodologically, studies have used elite athlete autobiographies to examine depression and other mental health-related issues. Newman and colleagues (2016) noted that even though the topic of mental illness was strongly associated with stigma, autobiographies exploring athletes and their personal experiences with these issues were exceptionally marketable. McGannon and McMahon (2016) explored the potential contributions of sport psychology research that focused on media representations and athlete identity. They argued that the media is an influential and powerful platform for "cultural representation and circulation of ideologies" (p. 44). The lack of research in this area might be related to sport psychology's greater interest in athletic performance than issues of diversity and power embedded in cultural sources like the media (McGannon \& McMahon, 2016). The International Journal of Sport and Exercise Psychology recently released a position stand on mental health, performance, and development in athletes that addressed many aspects of athlete mental health especially associated with athlete-specific dangers (Schinke, Stambulova, Si, \& Moore, 2017). Within the popular media, however, there has been an increasing amount of positive coverage of elite athletes and mental illness. Recently, Michael Phelps was part of a CNN news feature where he revealed his thoughts and openly discussed mental illness: "As an American it's (seen as) weakness when you ask for help and in our country, it's just not what you do. It took me a while to get to that point where it's OK to ask somebody for help" (Murphy \& Wire, 2017, p. 4).

While there has been a slight increase in literature focusing on mental health and illness in the athletic population and a number of studies that address the portrayals of mental illness in the media, no research studies have addressed bipolar disorder, a specific athlete, and the way the media represented the athlete with mental illness. Therefore, the purpose of this study was to examine media representations of Suzy Favor Hamilton's self-representation and open discussion of her bipolar disorder surrounding the time frame of her book release. Ethnographic content analysis (ECA) was used as a methodological approach for this study because it allowed for a critical examination of mental illness in the media. Specifically, understanding the way media represented Favor Hamilton's bipolar disorder allowed for insight into how media representation might impact societies' view of mental illness, specifically in the elite athlete population. Finally, while not grounded in any particular theoretical framework, the analysis leans on the work several scholars who have used feminist (and more recently postfeminist) 'sensibilities' (Cooky, 2018) to examine media representations of high-level female athletes. More specifically, we found the work of Fink, Kane, and LaVoi (2014), Toffoletti (2016), Bruce (2016), and others useful in connecting our analysis of Suzy Favor Hamilton to the previous literature on the sexist portrayals of other elite female athletes, while we also found the work of Cooky (2016) and others on postfeminist analysis useful in making sense of the nuanced times that Favor Hamilton's attempts to tell her own story of athletic identity, motherhood, and mental illness were met with overtly sexist responses, leading to "a simultaneous doing and undoing of feminism” (Cooky, 2016, p. 36).

\section{Method}

\section{Key Media Incident}

Suzy Favor Hamilton was a prominent middle-distance runner who earned nine NCAA championship titles and made three Olympic Games appearances. Although she never won a medal at the Olympic Games she always seemed to make headlines for her athleticism, beauty, and overall sweet hometown-girl appeal (Hamilton \& Tomlinson, 2015). Many components of Favor Hamilton's life could warrant evaluation of a key media incident. The release of her autobiography, Fast Girl: A Life Spent Running from Madness, was an incident that prompted media attention and discussion of mental illness in athletics. Production of this autobiography was ultimately sparked when Favor Hamilton's double life as a Las Vegas escort was exposed (Hamilton \& Tomlinson, 2015). Favor Hamilton received a public shaming that was described as "a flaying by the media" (Callahan, 2015, p. 1). Almost three years after her public outing, Favor Hamilton released Fast Girl which chronicled her life story as an Olympic athlete, her continuous struggle with mental illness, her Las Vegas escapades, and recognition and explanation of how bipolar disorder was the true cause of her Las Vegas call girl days (Hamilton \& Tomlinson, 2015). Favor Hamilton's book release collected media attention because of her in-depth descriptions of manic episodes and her open discussion of her bipolar disorder.

\section{Data Collection}

Articles were gathered through three databases: LexisNexis Academic, Factiva, and ProQuest News and Newspapers. For the purpose of this study the date range of November 14, 2014 (announcement of book release) to September 14, 2016 (one year after Fast Girl was available for purchase) was chosen. This allowed for book release promotion and post-publication appearances and articles. 'Suzy Favor Hamilton' was the search topic to ensure that all available media involving her book release and talk of mental illness were included. These search parameters were consistent with studies evaluating media and a specific athlete (Seear \& Fraser, 2010). Since the databases included did not include magazine articles, it was important to include the media section from www.suzyfavorhamilton.com and the top twenty 
from the list of the "Best 50 Culture Blogs and Websites on the Web" because cultural blogs and websites are often used for consumer information on public issues and stories. Articles were excluded if they were not related to the topic, not within the date range, duplicates, not in English, or if it only included comments unrelated to Fast Girl, her mental illness, or her running career. After delimitation, 35 articles were analyzed.

\section{Analysis}

With respect to epistemology, this study was firmly situated within a constructionist paradigm and more generally within the interpretivist paradigm of knowledge (Sparkes \& Smith, 2014). It was understood the media worked to construct understandings of mental illness, in this case bipolar disorder, as well as gender norms. ECA was used as the approach to evaluate the media involved in this study. As described by Altheide and Schneider (2013), this approach examined how meanings were formed and communicated within news media while validating the theoretical relationships that currently existed. Analysis involved repetitive movement between sampling, collection, coding, and interpretation of data. General coding allowed for an individual data point to be used in multiple thematic areas, a distinguishing feature of ECA. This criterion created an overlap between the sub-themes that settled under one overarching theme. The content of data was analyzed based on the actual data and the context of the data.

Newspaper, magazine, and online articles were collected based upon the aforementioned sampling criterion. To follow the best possible criteria for ECA, each article was read thoroughly before any coding occurred (Altheide \& Schneider, 2013). Once the general content and information in each article was grasped, the paragraphs in the articles were assessed for overall tone. Since similar and/or identical quotes and excerpts from Favor Hamilton's autobiography were used within many of the articles, the tone and context in which they were used was important for coding and overall analysis.

Each individual article was coded separately with a reference sheet in excel of the researcher's thoughts and codes. As suggested by Altheide and Schneider (2013), a protocol sheet was used to guide the analysis of each article. The protocol sheet included the following: Mental Health/Illness Related, Family Related, Prostitute Related, Career Related (runner), Exposure Related, and About Book. An "Other" category was also included which allowed for new thoughts and categories to emerge later on in the analysis. These initial categories on the protocol sheet were then reformatted for a better organizational component to the research.

Codes were evaluated, re-assessed, and organized in order to develop the overall theme of the articles evaluated as well as the three sub-themes that emerged from the collection of data (Altheide \& Schneider, 2013). With respect to what Tracy (2010) calls "quality" in qualitative research, two important measures were taken. The second author provided input throughout the analysis process and served as a "critical friend" during the coding of the data and the development of the themes from their rough, initial form to their final version. During their numerous meetings during the data analysis phase, the second author also presented negative cases to the first author, and constantly challenged the first author with regards to which codes eventually ended up within each of the themes.

Finally, Favor Hamilton's autobiography was used as a tool to determine if book references used by the media were in context or out-of-context. Athlete autobiographies in prior research studies have been used as an important analytical tool as well as a pedagogical resource in evaluating behavior, mental illness, and examination of the socially constructed experiences through the self-presentation of story telling (Newman et al., 2016; Schinke et al., 2017). Although this was not the intention of this study, Favor Hamilton's voice and excerpts from her book were used by the media frequently to represent her image and tell a story.

\section{Results and Discussion}

The media are "one of the most powerful institutions on this planet" especially in the context of sports (Kane, LaVoi, \& Fink, 2013, p. 276). Media representations could drastically make or break a sports star (Tulle, 2016). The data showed that Favor Hamilton was conscious of the power the media possessed because she was nervous about the response to her autobiography. However, she defended her choice to include extensive coverage of her detailed escapades in her interview with the Wall Street Journal:

The reason for that is just to show the destruction of the disease and the illness and show how it ruins lives and tears marriages apart. It tears relationships apart. And if people don't want to read that, they should know ahead of time that that is in the book. (Derby, 2015, p. 2)

Favor Hamilton's autobiography was perceived by many media sources as an opportunity for her to revel in her former hidden life and disclose the details of her sexual encounters (Italiano, 2015). In reality, Favor Hamilton saw it as her opportunity to help others by sharing her struggle and raise awareness of mental illness especially in the athletic population.

Omission of mental illness in the environment of athletics was the overarching theme that developed through data analysis. It was rooted in the broad socio-cultural concept that physical injury is significantly more acceptable and covered more often in sport than mental illness (Newman et al., 2016). Omission is defined in Merriam-Webster's Dictionary as "something neglected or left undone" and "apathy toward or neglect of duty." So, the overarching theme was characterized throughout this results section as neglecting to acknowledge mental illness. Dismissal of Favor Hamilton's mental illness as legitimate, ignoring mental illness signs and symptoms, and lack of mental illness education and awareness all represented a form of neglect of mental illness in the athletic environment and showed the trivialization of mental illness as a part of sport culture.

This overarching theme presented with three sub-themes that were identified from the media analysis: 1) Favor Hamilton as a disgrace, 2) Favor Hamilton's chronicle of battling mental illness, and 3) Favor Hamilton advocating change and awareness. The negative framing of mental illness that was represented in the overarching theme was further contextualized in each sub-theme by representing the most common challenges of mental illness in athletics. Specifically, Favor Hamilton's open discussion of bipolar disorder was most often presented in the media in three different ways: hypersexuality as a mental illness symptom, Favor Hamilton's complete mental illness history, and Favor Hamilton's role as a mental illness advocate. Each representation was further discussed in one of the three sub-themes, respectively. Each subtheme also incorporated a unique gendered component. The first sub-theme recognized the images of the ideal mother and wife, the second incorporated the epitome of a female athlete, and the third included opposition of traditional gender ideology. 


\section{Favor Hamilton as a Disgrace}

The sub-theme of Favor Hamilton as a disgrace included the portion of her bipolar disorder story that was consistently portrayed negatively by the media. In this sub-theme, the media either marginally recognized or did not recognize mental illness at all. The data showed that excerpts from her memoir were most often incorporated into popular media articles in a way that depicted her as a troubled individual:

Just a few months in, Favor Hamilton had all but abandoned her husband and child. They couldn't compete with clients who bought her thousand-dollar meals, took her on shopping sprees, sent her for spray tans and manicures. And, of course, there was the sex. She would travel to clients, or use business trips-such as a September 2011 appearance at the Disney Exhibit Hall-as opportunities for rendezvous. When her daughter called her in Vegas, Favor Hamilton was annoyed. (Callahan, 2015, p. 4)

The media also framed her actions as a result of fundamental flaws in her as a person, rather than her mental illness. The gendered nature of the coverage was seen in this sub-theme through representations of Favor Hamilton as a disgrace as a mother and wife. Overall, the sub-theme displayed how the media omitted Favor Hamilton's mental illness story as a legitimate cause of her activities in Las Vegas and her absence as a mother and wife.

An athlete's identity after a scandal is often constructed by negative media representations, and these representations can be particularly harmful in a sex scandal. Meng and Pan (2013) addressed athletes' statuses as role models and focused on image restoration after a sex scandal by using three prominent male athletes. Media coverage of Favor Hamilton related directly to this work, particularly since the narratives often centered on her working as an escort in Las Vegas while married with a child. Media coverage consistently showed that image restoration for Favor Hamilton even as a traditionally attractive, female, athlete would be difficult at best:

'When my story came out, I was shamed.' she said. 'I was called a whore, slut, every word imaginable. I was told how awful I was. I was told to kill myself like my brother did . . I I was shamed immensely. [So] immensely that shame almost took my life, I don't want to shame escorts for a path-we have no idea why they chose that path. I will not shame them, I will humanize them. I think as a society ... we need to understand, instead of crucify.' (Spain, 2015, p. 3)

This quote exemplified how Favor Hamilton was treated as a female involved in a sex scandal. As Bruce (2016) noted, portrayals of the differences between males and females are important because it illustrates the variations in gender roles across cultural and historical contexts and distinguishes differences between traditional and contemporary masculine and feminine norms. By mentioning escorting as an acceptable career, she further distanced herself from "acceptable" gender norms and "suitable" female behavior. Even though her sex scandal was similar in many ways to those of her male athlete counterparts, Favor Hamilton's image was framed as seemingly irreparable.

Gender ideology and its relationship with the mainstream sports media has been an accepted as a natural part of sport (Bruce, 2016; Kane et al., 2013; Thorpe, Toffoletti, \& Bruce, 2017). Although concepts such as third-wave feminism have challenged traditional gender ideology, Bruce (2016) suggested that women in sports are still frequently and successfully "packaged" as wives and mothers. Therefore, within this sub-theme of Favor Hamilton as a disgrace, her life as an escort was often presented in the media as irresponsible. Defying gender ideology was a concept that appeared in the data frequently as it related to her inability to perform proper female duties. Callahan (2015) displayed Favor Hamilton as indifferent about her duties as a female and her priorities as a mother and wife in her article:

In her new memoir, 'Fast Girl: A Lifetime Spent Running from Madness,' Favor Hamilton is far less apologetic about her year spent hooking or the damage it caused her husband and child - in fact, those passages are the book's most detailed and vibrant. (p. 1)

These quotes displayed Favor Hamilton's actions as careless and selfish. Specifically, culture 'tells' us women are more adept for childcare than men and what activities are acceptable for mothers (McGannon, Gonsalves, Schinke, \& Busanich, 2015). In both cases, Favor Hamilton was frequently presented in the media as a failure. This was contrasted significantly with media representations of Favor Hamilton's husband, Mark. He was frequently portrayed as a strong and heroic figure because he preserved their daughter's naivety, protected Favor Hamilton's running image, and maintained the family business alone. When Mark discovered that Favor Hamilton's actions were due to her bipolar disorder, he saw past her marital indiscretions and focused on getting her help. The representation of Mark's sacrifice did not, of course, influence or alter cultural perceptions of Favor Hamilton as an unsuitable wife and mother. Although her illness was valid and diagnosed, the data showed that media sources blamed her character for her inappropriate actions instead of accepting hypersexuality as a symptom of bipolar disorder. As Callahan (2015) again opined:

Sex, for Favor Hamilton, was replacing her runner's high. She never really explains why she needed sex with strangers, but she intermittently claims she, too, suffers from bipolar disorder and was improperly medicated during this period of her lifealthough in the book, she reports none of the lows that always follow a bipolar patient's manic episodes. (Callahan, 2015, p. 2)

The Favor Hamilton as a disgrace sub-theme also included how open discussion of sex in her book further altered the perception of her as a loveable star and prompted headlines like: "Boff and running Olympian: I'm happy as a hooker", "Oh-OhOlympics! Being a hooker was better than gold”, and " 'Trick' star Many Excuses_-but no regrets-for Olympic runner who ditched family to live the fast life as a Vegas prostitute." The data included headlines, like the ones above, to present Favor Hamilton as a scandalous and sex-crazed former Olympian who rerouted her life to become a Las Vegas escort purely out of personal desire and pleasure. Her memoir was also trivialized by the media when it was directly compared to "Fifty Shades of Grey" and described as "so breezy, engaging, and titillating" (Derby, 2015, p. 1). Descriptions like this one, as well as book excerpts taken out-of-context, were often used to portray Favor Hamilton as out of control:

A former Olympic athlete has revealed working as a high-class hooker gave her a bigger thrill than winning races. Suzy Favor Hamilton, 47, also says she misses getting paid for sex and still craves it like a drug. The American former athlete said: 'I'd devoted myself to sex and my need to be unsurpassed in the bedroom had replaced the need to be best on the track.' (Allen, 2015, p. 1) 
There were several articles like this, which focused on Favor Hamilton's actions in Las Vegas while simultaneously downplaying her incredible athletic success. As the work of sport sociologist Mary Jo Kane and colleagues have shown for decades, the media often sexualize even the most elite of competitors, and given Favor Hamilton's condition both sport media and gossip outlets continued this trend.

This sub-theme demonstrated that the media often dismissed and/or minimized bipolar disorder as a latent cause of Favor Hamilton's prostitution activities. When an article specifically looked to minimize bipolar disorder it often used the mental illness as an excuse argument, "Hamilton was exposed as a high-priced call girl in 2012 and swore off the lifestyle in a rambling online apology that blamed chronic depression but revealed nothing salacious" (Italiano, 2015, p. 1). Excerpts like this one were generally toned as negative and relied on the tactic of representing Favor Hamilton as a liar. DeLenardo and Terrion's (2014) research results supported the media's premise that mental illness can be used as a defense of poor life decisions. The data showed that according to some media sources Favor Hamilton's mental illness was seen as very unlikely and convenient. Overall, the dismissal of mental illness as a factor in Favor Hamilton's escorting days intensified negative media exposure.

\section{Favor Hamilton's Chronicle of Battling Mental Illness}

This second sub-theme related to the lifelong challenges Favor Hamilton faced as a person who suffered from mental illness. Before her diagnosis with bipolar disorder, Favor Hamilton suffered from symptoms that were intensified by the constant pressure she felt to maintain a picture perfect image. In this sub-theme, Favor Hamilton's bipolar disorder was specifically seen as a contributing factor to her actions as an escort. Overall, this subtheme explored the negative challenges and perceptions of mental illness.

In Favor Hamilton's memoir she explained her family life and their collective struggles with mental illness. Specifically, her brother's bipolar disorder was mentioned as a lingering pain that was felt by all of her family members. At a very young age, Favor Hamilton decided that perfection was the best solution to ease her parents' pain. However, her perfectionism eventually led to stress and internal pressure that was exemplified in this thought processes within her autobiography:

Sure, I wanted to win. I liked to win, But, in truth, I needed to win, Even as I stood with my teammates, receiving my medal, the wheels in my head were turning. Now I have to win every state meet I ever run. There's no choice, If I were to lose, I'd let everyone down-my parents, my coach, my community-and that can't happen. And thus began a cruel cycle in my life. The more obsessed I became, the faster I ran; the faster I ran, the more notoriety I received; and the more notoriety I received, the more obsessed I became. Soon, even winning wasn't enough. (Hamilton \& Tomlinson, 2015, p. 26)

Sports culture emphasized the importance of winning, but at the very beginning of her career some of Favor Hamilton's anxiety was self-inflicted. She believed that winning races allowed her parents to live in an alternative happy reality. Her anxiety later manifested itself as different eating disorders, which she explained in an interview on BBC Radio:
I did everything at a mile a minute and couldn't focus for the life of me. Growing up, I lived with an eating disorder, had suicidal thoughts and a suicide attempt in college, then experienced severe anxiety when I raced. But I kept it all in, trying to maintain the facade of the perfect Midwestern girl, strong and powerful. (Hamilton, 2016, p. 1)

This was an issue that plagued Favor Hamilton for most of her career and is also common in the environment of athletics (Markser, 2011; Reardon \& Factor, 2010; Rice et al., 2016; Schinke et al., 2017). The inclination for Favor Hamilton to conceal her "inner demons" might have stemmed from a conservative Wisconsin upbringing or from the tendency of athletes to internalize their emotional problems because of the fear of negative public stigmas (DeLenardo \& Terrion, 2014).

Favor Hamilton was able to conceal some of her mental illness symptoms, but other symptoms and warning signs were often ignored because of her remarkable success (Hamilton, 2016). One article even described Favor Hamilton's aforementioned struggles as a "hidden cost" for her success "in a culture that encouraged and enabled her undiagnosed illness" (Gupta, 2015, p. 1). Avoidance and minimization of mental health issues and psychological distress was common in sports culture because of the presumption that mental strength and toughness are inherent athlete qualities (Carr \& Davidson, 2014).

Favor Hamilton's chronicle of battling mental illness also included how Favor Hamilton adopted an idealized female image. Her perpetual need to maintain this image started at a young age and continued throughout her athletic career. Carless and Douglas (2013) explained that identity was a socio-cultural product of narratives, not an individual self-construction. "When a single narrative type becomes dominant, it overrides or silences alternative stories. As a result, it can come to exhibit a disproportionate influence on individuals' lives" (p. 702). This ingrained mindset and pressure to maintain perfection was presented in some of the data as Favor Hamilton's only option, as it was constantly reinforced by her parents, coaches, and other external pressures as she progressed throughout her athletic career:

The anxiety that I've had my entire life was just so much to deal with, and I had never really spoken up because I thought if I speak up about my insecurities or that I have a weakness, I am showing other athletes that I am weak. They will have an advantage over me. I always kept everything inside, and that pressure just built. (Gray, 2015, p. 1)

The immense pressure to remain perfect was often emphasized in female athletes especially. As Thorpe and colleagues (2017) noted, female athletes who epitomized attractiveness and success were ultimately placed into narratives that increased pressures and expectations to act as an icon for their sport and be positive role models.

Articles that considered Favor Hamilton's bipolar disorder diagnosis as real stated that her antidepressant medication intensified her manic urges and ultimately caused her hypersexuality. Her manic states were described as being out of her control and as an enemy that needed to be fed to remain satisfied. Another way that Favor Hamilton explained the manifestation of her bipolar disorder was the use of two separate personas. Describing the disease as two separate people was a way to distinguish how bipolar disorder affected her actions. Specifically, in her interview with Cosmopolitan she explained this: 
I think it will be easy for people to read this book and then when they see me, possibly think I am that person. I am not that person in the book. That was Kelly, the unhealthy person. I fully see what I did was wrong and wrong for me to be doing that. I'm not judging other women who are in this profession, but for me, definitely this was wrong. I want people to understand that - that when you do read this book and you read the crazy sexual experiences that I had in here, that was Kelly. That was the bipolar looking for the heightened sexuality. That was that person. She could continue on with risky behavior and never have a care in the world about it. I guess I want people to look at this book and open up their eyes and hopefully it'll change somebody that can have more compassion and less judgment. (Gupta, 2015, p. 3)

The two identities, Kelly and Suzy, starkly contrasted each other, which exemplified trademark characteristics of bipolar disorder (Grande, Berk, Birmaher, \& Vieta, 2016). This strategy also helped Favor Hamilton show that bipolar disorder directly influenced her decisions. Even though mental illness was seen as taboo, accepting her actions as her fault was seen as admirable even if it did not help restore her idealized female image.

Media reactions to Favor Hamilton's open discussion of her longstanding struggles with mental illness were also present in this sub-theme. The media reactions' toward Favor Hamilton's bipolar disorder were consistent with how mental illness was most often represented in the media (Anderson, 2003; Ma, 2017). Vivid descriptions like "crippling symptoms", "dark", and "wreaked havoc" were used to describe Favor Hamilton's bipolar disorder. These descriptions highlighted the experience of mental illness and the negative cultural stigmas toward them. In many cases the media also represented Favor Hamilton as reinforcing stigmas towards mental illness. She often used words like "crazy" and "bizarre" to describe herself and others as well as the behaviors that are associated with mental illnesses. Use of these words was in agreement with common stigmatized beliefs about mentally ill individuals that were prevalent in the media and by doing so might have unintentionally reinforced these stereotypes (Anderson, 2003; Fauteux et al., 2008; Ma, 2017; McGinty et al., 2014; Mellifont \& Smith-Merry, 2015; Quintero Johnson \& Riles, 2016).

\section{Favor Hamilton Advocating Change and Awareness}

The final sub-theme that emerged was Favor Hamilton advocating change and awareness. Post-book release appearances presented a platform for Favor Hamilton to discuss her struggles with and recovery from mental illness with complete transparency. This demonstrated how Favor Hamilton's open discussion of her mental illness and sexual promiscuity challenged cultural norms. These specific actions placed Favor Hamilton into an uncharacteristic female role as a strong and confident woman. Coping with her mental illness, and the unique circumstances surrounding it, placed Favor Hamilton into a mental illness advocate role and to some she was even a positive role model. Overall, this sub-theme discussed lack of mental illness education and awareness.

The media often referred to Favor Hamilton's memoir as using unflinching detail, startlingly frank, scandalous, a risky choice, and revealing. Even though escorting was prompted by Favor Hamilton's unruly manic states, she described her escorting days as important for her growth and development as a person. Favor Hamilton said escorting brought her independence, a voice she did not know she had, and the confidence to believe that she could take care of herself (de Long, 2015). However, Favor Hamilton frequently admitted to escorting as a mistake for her, but always made it clear that she had nothing against the profession:

But the one thing I despise is how women who escort are treated by most of America. The stigma, the shaming, etc. You have to be so strong to be in this business and survive. I . . . respect . . . those who can pull it off. Total badasses. (de Long, 2015, p. 4)

Favor Hamilton was also not ashamed that she worked as an escort because escorting allowed her to challenge the idealized female image that she was expected to live up to. This idea is further described by Harms, who noted that, "She liked how she could finally please, how insignificant it made the world of running, how it defied others' expectations of her" (2016, p. 2). Favor Hamilton's e-mail exchange with de Long also exemplified this, "I believe part of my choice to become an escort was an underlying desire to be the 'bad girl' for once ... . For once, I could have control of my life, my body" (2015, p. 2).

The open acceptance of prostitution, especially as a female, was not common in most western cultures. As Conley, Ziegler, and Moors' (2012) stated, there was a sexual double standard when male and female sexuality was discussed. Females were, "stereotypically expected to be generally uninterested in sexuality outside relationships, protective of their sexual 'honor', and interested in sex in relationships only to please the man involved" (p. 2). The analysis showed that Favor Hamilton engaging in these activities herself and supporting the profession of escorting created turmoil and discomfort in the conservative expectations of society. Openly opposing gender expectations can also cause discrimination because there are staple societal perceptions of female athletes in sports culture (Bruce, 2016).

Favor Hamilton's advocacy efforts and sharing her mental illness story revolved around her determination to, "raise awareness, provide understanding, and offer inspiration" to anyone who was working through their own personal struggles (Butler, 2015, p. 1). Although extremely painful, she believed writing her memoir was necessary in order to educate others on mental illness, convey what bipolar disorder may look like, reduce stigma, and ultimately show that there is hope on the other side of darkness. Favor Hamilton described, in her conversation over e-mail with de Long (2015), how her lowest points of mental illness ultimately rescued her from a predominantly closed minded culture:

I speak up when I'm not comfortable with something. When somebody is pissing me off, I let them know. I used to let people walk all over me. Not anymore. I wear what I want, I say what I want. It's liberating. (p. 3)

Another recurrent finding in the data was Favor Hamilton working to show others that it was okay to be comfortable in your own skin and embrace the challenges that come along with mental illness instead of fighting them to conform better to societal expectations:

'I absolutely love that I'm no longer perfect!' Hamilton said. 'I embrace it so much now. I was telling somebody, I like to be messy. I like to be sloppy. And I like to throw my paint all over a canvas! That's who I am! And what an exhilarating, freeing feeling it is to now live a life that's truly how you want, not how others want your life to be.' (Spain, 2015, p. 3) 
Media portrayals of her new attitude about life and perception of society coincided with explanation of third wave feminist characteristics (Bruce, 2016; Thorpe et al., 2017). Thorpe et al. (2017) described third wave feminists as welcoming ideas of "messiness, complexity, multiplicity, a nonjudgmental attitude toward women's cultural productions, and an attempt to think outside existing gender, sexuality, and race binaries" (p. 363). Even though some news media stated that Favor Hamilton's intention was to spread her mental illness story, there is no denying that her actions to stand up for her beliefs and portray mental illness as acceptable in society placed her as a third wave feminist.

Favor Hamilton's advocacy efforts and image as a positive role model were not as frequent as the negative representations. However, some data showed that many people claimed to be touched, encouraged, and inspired by Fast Girl. A sports columnist for Good Morning America stated, "Of all of your achievements on the track, this might just be the greatest one with all of the people it could help" (ABC News, 2015, p. 4). Other media sources mirrored this opinion. In one article, Favor Hamilton stated that her new life aspirations were far more honorable than competing to win a gold medal. She embraced the challenge of talking about mental illness issues in a society where mental illness is commonly misrepresented (Anderson, 2003; Quintero Johnson \& Riles, 2016). One statement that enveloped the perceived positive impact Favor Hamilton made by sharing her story was made by long time race announcer Rudy Novoton: "Sometimes what defines you," he said, "isn't how you act when everything's perfect" (Harms, 2016, p. 4).

\section{Limitations}

Even though this data analysis included a wide range of articles about Favor Hamilton's book release, there were some limitations. Articles that contained very similar content were eliminated and only one version was analyzed. Exclusion of articles did not allow for the examination of consistency of occurrence. Also, the intent of this article was to discover common media representations of mental illness. Since Favor Hamilton's story was strongly associated with an escorting component, it was difficult to decipher the negativity towards her as an escort and her suffering from mental illness. However, the articles collected and the data analyzed did allow for a through analysis of the most common media representations of Favor Hamilton's book release.

\section{Conclusions}

This study attempted to attain a better understanding of how the media represented Favor Hamilton's open discussion of bipolar disorder. ECA revealed that discussion of mental illness was often omitted in the environment of high-level athletics. While there were some positive perceptions, overall the analysis emphasized that open talk of mental illness in the media was rare. It also showed that when mental illness was discussed, it was often presented with negative connotations, a finding consistent with previous work on media representations of mental illness (Ma, 2017; Mellifont \& Smith-Merry, 2015; Quintero Johnson \& Riles, 2016). However, the representations of mental illness relied heavily on the type of article that was evaluated. Many of the articles used direct quotations, interview techniques, self-written articles, or excerpts from her book to convey a message. The majority of the positive undertones were a result of times when Favor Hamilton was essentially able to represent herself, something which speaks to the recent increase in high profile elite athletes speaking out in public about their own mental health issues.

Out-of-context references related to sexual experiences in Favor Hamilton's book were often used to place her in a negative light. Information that was not essential, like how much money she made and whom she was sleeping with, was placed in the article to increase the salacious nature of her actions, in the process further stigmatizing that part of her bipolar disorder. Her book also used multiple voices and perspectives to convey her state of mind in the moment of her actions. These state-of-mind quotations were frequently not used in their entirety or in proper context, which at times made it seem like Favor Hamilton was still escorting or planned to escort again. Incorrect information about when she began escorting, how many children she had, and her mental illness diagnosis were also found in articles that represented her with an overall negative tone.

Representations of Favor Hamilton might have been exceedingly harsh because of her drastic change in female roles. Favor Hamilton failed to bring home an Olympic medal on three separate occasions and also admitted to intentionally collapsing during her third Olympic appearance. Interestingly, these failures within the sporting domain were not portrayed as negatively as Favor Hamilton's failure as a woman. Even with restoration efforts, Favor Hamilton's tainted reputation as a mentally ill, promiscuous woman remained. Favor Hamilton's mental illness story was also unique because of the increased hypersexuality component that is not present in other mental illnesses and not even all cases of bipolar disorder. Thus, it might be possible for an athlete to be received more positively if he or she only challenged mental illness in sports culture and did not challenge gender norms. Read through the lens of "postfeminist sensibility" (Cooky, 2018), it is clear that in addition to the ongoing stigmatization of bipolar disorder in athletes and in the media in general, the perceived disruption of traditional gender relations remains the key issue in making sense of Favor Hamilton's representations.

It was important to understand representations of mental illness in the media to gain knowledge about what was culturally accepted and what was not. There was minimal research on representations of athletes with mental illnesses, although there has been an increase in the amount of research on self-representations of depression, anxiety, and eating disorders using athlete autobiographies. There were few research studies that addressed the effect of negative or positive media representations on mental illness. Overall, mental illness in the elite athletic population has not been addressed. Any research on this topic might be beneficial for gaining a better understanding of the socio-cultural representation of mental illness. Further research can be done to address this gap in the literature as well as research that evaluates the differences between male and female athlete sex scandals related to mental illness.

\section{References}

Allen, F. (2015, September). Oh-oh-ohlympics! Being a hooker was better than gold. The Scottish. Retrieved from https://www.thesun.co.uk/ archives/news/81707/oh-oh-ohlympics-being-a-hooker-was-better-thangold/

Altheide, D., \& Schneider, C. (2013). Qualitative media analysis (2nd ed.). Thousands Oaks, CA: Sage Publications.

American Broadcasting Company News: Good Morning America. (2015, September 14). Former Olympian reveals secret life: Suzy Favor 
Hamilton doubled as escort. Retrieved from https://global-factivacom.libaccess.sjlibrary.org/ha/default.aspx\#./!?\&_suid=1524894206 95308361429578297044

Anderson, M. (2003). 'One flew over the psychiatric unit': Mental illness and the media. Journal of Psychiatric and Mental Health Nursing, 10(3), 297-306. PubMed ID: 12755914 doi:10.1046/j.1365-2850. 2003.00592.x

Aoki, A., Aoki, Y., Goulden, R., Kasai, K., Thornicroft, G., \& Henderson, C. (2016). Change in newspaper coverage of schizophrenia in Japan over 20-year period. Schizophrenia Research, 175(1-3), 193-197. doi:10.1016/j.schres.2016.04.026

Beable, S., Fulcher, M., Lee, A., \& Hamilton, B. (2017). SHARPSports mental Health Awareness Research Project: Prevalence and risk factors of depressive symptoms and life stress in elite athletes. Journal of Science and Medicine in Sport, 20(12), 1047-1052. PubMed ID: 28601589 doi:10.1016/j.jsams.2017.04.018

Bruce, T. (2016). New rules for new times: sportswomen and media representation in the third wave. Sex Roles, 74(7-8), 361-376. doi:10. 1007/s11199-015-0497-6

Butler, L. (2015, November 11). Olympic runner, advocate, author and former escort to address hundreds at 11/24 San Diego luncheon. PRNewswire. Retrieved from https://global-factiva-com.libaccess. sjlibrary.org/ha/default.aspx\#./!?\&_suid=1521127372285054497521 65232427

Callahan, M. (2015, September 20). Trick' star Many excuses - but no regrets - for Olympic runner who ditched family to live the fast life as a Vegas prostitute. New York Post. Retrieved from https:// global-factivacom.libaccess.sjlibrary.org/ha/default.aspx\#./!?\&_suid= 15211274505030026101075119368877

Carless, D. \& Douglas, K. (2013). Living, resisting, and playing the part of athlete: Narrative tensions in elite sport. Psychology of Sport and Exercise, 14(5), 701-708. doi:10.1016/j.psychsport.2013.05.003

Carr, C., \& Davidson, J. (2014). Mind, body and sport: Understanding and supporting student-athlete mental wellness. Indianapolis, IN: NCAA.

Conley, T. D., Ziegler, A., \& Moors, A.C. (2012). Backlash from the bedroom: stigma mediates gender differences in acceptance of casual sex offers. Psychology of Women Quarterly, 37(3), 1-16.

Cooky, C. (2018). What's new about sporting femininities? Female athletes and the sport-media industrial complex. In K. Toffoletti, J. Francombe-Webb, \& H. Thorpe (Eds.), New sporting femininities: Embodies politics in postfeminist times (pp. 23-41). Cham, Switzerland: Palgrave-Macmillan.

DeLenardo, S., \& Terrion, J. (2014). Suck it up: opinions and attitudes about mental illness stigma and help-seeking behaviour of male varsity football players. Canadian Journal of Community Mental Health, 33(3), 43-56. doi: 10.7870/cjcmh-2014-023

de Long, K. (2015, November 5). Not good For me: An interview with Suzy Favor Hamilton. Katie Around the internet, News. Retrieved from http://titsandsass.com/not-good-for-me-an-interview-with-suzyfavor-hamilton/

Derby, S. (2015, September 20). Favor Hamilton says she 'lost touch with reality'. Wisconsin State Journal. Retrieved from http://host.madison. com/wsj/sports/running/suzy-favor-hamilton-says-she-lost-touch-withreality/article_47c3640c-79ef-5705-8c75-4d02ca127921.html

Fauteux, D., McKelvie, S., \& Man, A. (2008). Effects of exposure to public figures' use of psychologists on attitude towards help-seeking behavior. North American Journal of Psychology, 10(2), 385-396.

Fink, J. S., Kane, M. J., \& LaVoi, N. M. (2014). The freedom to choose: Elite female athletes' preferred representations within endorsement opportunities. Journal of Sport Management, 28, 207-219. doi: 10. 1123/jsm.2013-0101
Gibson, K., \& Gorczynski, P. (2019). Mass mediation of mental illness in sport. In M. Atkinson (Ed.), Sport, mental illness, and sociology (pp. 143-159). Bingley, UK: Emerald Publishing.

Grande, I., Berk, M., Birmaher, B., \& Vieta, E. (2016). Bipolar disorder. The Lancet, 387(10027), 1561-1572. doi: 10.1016/S0140-6736(15) 00241-X

Gray, M. (2015, September 9). Suzy Favor Hamilton talks about her secret life as a Las Vegas escort. Sports Illustrated Online. Retrieved from https://www.si.com/more-sports/2015/09/09/suzy-favor-hamiltoninterview-life-escort

Gucciardi, D., Hanton, S., \& Fleming, S. (2017). Are mental toughness and mental health contradictory concepts in elite sport? A narrative review of theory and evidence. Journal of Science and Medicine in Sport, 20(3), 307-311. PubMed ID: 27568074 doi:10.1016/j.jsams.2016. 08.006

Gupta, P. (2015, September 16). Former Olympian opens up about her time as a Vegas escort and her battle with mental illness. Cosmopolitan. Retrieved from https://www.cosmopolitan.com/lifestyle/news/a46326/ suzy-favor-hamilton-olympian-vegas-escort-bipolar-memoir/

Hamilton, S. (2016, February 12). Suzy Favor Hamilton: Olympic athlete to Las Vegas escort. BBC Sport Retrieved from http://www.bbc.com/ sport/olympics/35552117

Hamilton, S., \& Tomlinson, S. (2015). Fast Girl: A life spent running from madness. New York, NY: Harper Collins.

Harms, R. (2016, January 18). Suzy Favor Hamilton is at peace, and running to inspire. San Diego Tribune. Retrieved from http://www. sandiegouniontribune.com/sports/sdut-suzy-favor-hamilton-is-atpeace-and-smiling-again-2016jan18-story.html

Italiano, L. (2015, September 10). Boff and running Olympian: I'm happy as a hooker. New York Post. Retrieved from https://www.pressreader. com/usa/new-york-post/20150910/283016873485209

Kane, M., LaVoi, N., Fink, J. (2013). Exploring elite female athletes' interpretations of sports media Images: A window into the construction of social identity and "selling sex" in women's sports. Communication \& Sport, 1(3), 269-298. doi:10.1177/2167479512473585

Knight, J., \& Giuliano, L. (2001). He's a laker; She's a "looker": The consequences of gender-stereotypical portrayals of male and female athletes by the print media. Sex Roles, 45(3), 217-229. doi:10.1023/ A: 1013553811620

Ma, Z. (2017). How the media cover mental illnesses: A review. Health Education, 117(1), 90-109. doi:10.1108/HE-01-2016-0004

Markser, V. (2011). Sport psychiatry and psychotherapy. Mental strains and disorders in professional sports. Challenge and answer to societal changes. European Archives of Psychiatry and Clinical Neuroscience, 261(2), 182-185. doi:10.1007/s00406-011-0239-x

McGannon, K. R., Gonsalves, C. A., Schinke, R. J., \& Busanich, R. (2015). Negotiating motherhood and athletic identity: A qualitative analysis of Olympic athlete mother representations in media narratives. Psychology of Sport and Exercise, 20, 51-59. doi:10.1016/j. psychsport.2015.04.010

McGannon, K. R., \& McMahon, J. (2016). Media representations and athlete identities: Examining benefits for sport psychology. QMiP Bulletin, 22, 44-53.

McGinty, E., Webster, D., Jarlenski, M., \& Barry, C. (2014). News media framing of serious mental illness and gun violence in the United States, 1997-2012. The American Journal of Public Health, 104(3), 406-413. PubMed ID: 24432874 doi:10.2105/AJPH.2013.301557

Mellifont, D., \& Smith-Merry, J. (2015). The anxious times. Asia Pacific Media Educator, 25(2), 278-296. doi:10.1177/1326365X15604937

Meng, J. \& Pan, P. (2013). Revisiting image-restorative strategies: An integrated case study of three athlete scandals in sports news. 
International Journal of Sport Communication, 6, 87-100. doi:10. 1123/ijsc.6.1.87

Murphy, C., \& Wire, C. (2017, July 7). Michael Phelps: 'I locked myself in my room for four days'. CNN, Cable News Network. Retrieved from www.cnn.com/2017/07/03/sport/olympics-michael-phelps-swimmingmental-health/index.html

Newman, H., Howells, K., \& Fletcher, D. (2016). The dark side of top level sport: An autobiographic study of depressive experiences in elite sport performers. Frontiers in Psychology, 7, 1-12. doi:10.3389/ fpsyg.2016.00868

Pike, E. C. J. (2019). Mental illness stigma. In M. Atkinson (Ed.), Sport, mental illness, and sociology (pp. 9-22). Bingley, UK: Emerald Publishing.

Quintero Johnson, J., \& Riles, J. (2016). "He Acted Like a crazy person": exploring the Influence of college students' recall of stereotypic media representations of mental illness. Psychology of Popular Media Culture, 7(2), 146-163. https://psycnet.apa.org/doi/10.1037/ ppm0000121. doi:10.1037/ppm0000121

Reardon, C., \& Factor, R. (2013). Sport psychiatry a systematic review of diagnosis and medical treatment of mental illness in athletes. Sports Medicine, 40(11), 961-980.

Rice, S., Purcell, R., Silva, S., Mawren, D., McGorry, P., \& Parker, A. (2016). The mental health of elite athletes: A narrative systematic review. Sports Medicine, 46(9), 1333-1353. PubMed ID: 26896951 doi:10.1007/s40279-016-0492-2

Schinke, R. J., Stambulova, N. B., Si, G. \& Moore, Z. (2017). International society of sport psychology position stand: athletes' mental health, performance, and development. International Journal of Sport and Exercise Psychology, 16(6), 1-18. doi:10.1080/1612197X.2017. 1295557
Schwenk, T. (2000). The stigmatisation and denial of mental illness in athletes. British Journal of Sports Medicine, 34(1), 4-5. PubMed ID: 10690441 doi:10.1136/bjsm.34.1.4

Seear, K., \& Fraser, S. (2010). The 'sorry addict': Ben Cousins and the construction of drug use and addiction in elite sport. Health Sociology Review, 19(2), 176-191. doi:10.5172/hesr.2010.19.2.176

Spain, S. (2015, September 15). Olympian-turned-escort Suzy Favor Hamilton reclaims a life rerouted by mental illness. ESPNW. Retrieved from http://www.espn.com/espnw/news-commentary/ article/13656143/olympian-turned-escort-suzy-favor-hamilton-reclaimslife-rerouted-mental-illness

Sparkes, B.S., \& Smith, A. (2014). Qualitative research methods in sport, exercise and health: From process to product. New York, NY: Routledge.

Thorpe, H., Toffoletti, K., \& Bruce, T. (2017). Sportswomen and social media: bringing third-wave feminism, postfeminism, and neoliberal feminism into conversation. Journal of Sport and Social Issues, 41, 359-383. doi:10.1177/0193723517730808

Toffoletti, K. (2016). Analyzing media representations of sportswomenexpanding the conceptual boundaries using a postfeminist sensibility. Sociology of Sport Journal, 33, 199-207. doi: 10.1123/ssj.2015-0136

Tracy, S.J. (2010). Qualitative quality: Eight 'Big Tent' criteria for excellent qualitative research. Qualitative Inquiry, 16(10), 837-851. doi:10.1177/ 1077800410383121

Tulle, E. (2016). Living by numbers: Media representations of sports stars' careers. International Review for the Sociology of Sport, 51(3), 251264. doi:10.1177/1012690214525157

Weigand, S., Cohen, J., \& Merenstein, D. (2013). Susceptibility for depression in current and retired student athletes. Sports Health: A Multidisciplinary Approach, 5(3), 263-266. doi:10.1177/1941738113480464 